\title{
I nnovating nursing education: interrelating narrative, conceptual learning, reflection, and complexity science
}

\author{
Gail J. Mitchell, Christine M. Jonas-Simpson, Nadine Cross \\ School of Nursing, Faculty of Health, York University, Canada
}

Correspondence: Gail J oyce Mitchell. Address: York University, HNE 349, 4700 Keele Street, Toronto, Canada. Email: gailm@yorku.ca.

Received: August 17, 2012

DOI : $10.5430 /$ jnep.v3n4p30
Accepted: September 17, 2012

URL: http://dx.doi.org/10.5430/jnep.v3n4p30

\section{Abstract}

This paper addresses innovations in nursing education that build on ideas from various educational theorists as well as principles of conceptual and narrative pedagogy. Authors inter-relate principles and theory from complexity science within a planned and actual nursing program to demonstrate how narrative, conceptual learning, reflection, and complexity science can come to life in nursing education. Specific processes informing the new nursing pedagogy are described: emergence with diversity, recursion/patterning, and transformative insights. Examples from a planned undergraduate curriculum and a graduate qualitative research course are provided. The complexity-inspired curriculum supports a teaching-learning environment that is student-centred, critical, generative, and inclusive.

\section{Key words}

Concept-based curriculum, Student-centred, Nursing education, Complexity pedagogy

\section{I ntroduction}

Nursing educators are responding to calls to integrate experiential, conceptual, and complexity science ideas into their professional programs and to shift from teacher as controller to teacher as enabler of student inquiry ${ }^{[1-4]}$. These changes are occurring simultaneously with increases in class size, elearning enhancements, and student diversity. We offer a view of curriculum development that is embedded within realities of narrative pedagogy, concept-based learning, reflection, and complexity science. For the purposes of this paper, we will focus on specific processes impacting our nursing education pedagogy: emergence with diversity, recursion/patterning, and transformative insights. Each of these processes will be considered and integrated with literature and examples from actual and proposed nursing curriculum.

\section{Educational transformation: Emergence in Time}

To consider the influences of 20th century education and curricular development on nursing education, we bring some theorists into our conversation in order to make explicit their persisting contributions in our work. The critical thinking of 20th century educators, such as Dewey ${ }^{[5]}$, Freire ${ }^{[6-8]}$, bell hooks ${ }^{[9]}$, and Mezirow ${ }^{[10]}$ inform our approach to nursing 
education. For Dewey ${ }^{[5]}$, the emphasis was to transform education from an institutional imperative to a student-centred endeavor. Dewey's learner-centred approach to curriculum development advises us that students' interests can guide their choices from a group of themes (concepts) identified by the teacher. Learning is active- $\mathrm{a}$ living process enriched in students' experiences of personal inquiry which can be transformative ${ }^{[11,12]}$. Dewey uses the biological metaphor of growth to demonstrate learning and increasing complexity of the system - of the learner ${ }^{[13]}$. The growth or learning arises from the continual integration and mutual influence between persons and environment, as the learners bring forth the meanings of their experience ${ }^{[14]}$.

Freire's ${ }^{[8]}$ first principle of educational philosophy involved the displacement of teacher as expert and the creation of a space where both teacher and learner bring their understandings, experiences, and ideas together to learn from each other. His two objectives for this new pedagogy were: "to explore what each knows and what they can teach each other and ....to foster reflection on the self as actor in the world in consequence of knowing” (p.8). In Freire's text, Pedagogy of Oppressed ${ }^{[7]}$, the educational perspective is one of emancipation of the person through development of a critical consciousness; such freedom illuminates the politics of education. Friere's conscientization process is not to create consciousness of oneself but to create group consciousness amid the struggles of class and classroom ${ }^{[15]}$.

Bell hooks ${ }^{[9]}$ translated conscientization into terms of critical awareness and engagement (p.14). Such engagement calls to each student to be an active participant in learning, not a passive consumer, thus bringing forth an emancipatory praxis action and reflection for both teacher and learner. She extends the teaching-learning process to community and invites reflection by teachers and students about who they are, how they value others-or not, how they serve others-or not, how they respect others-or not. Her links with reflection and the continuous questioning about: Who am I becoming? connects with Mezirow’s ${ }^{[10]}$ insights on critical reflection.

Jack Mezirow's ${ }^{[10]}$ educational theory concerning critical reflection as an impetus for transformative learning continues to influence adults and educators of adults. For Mezirow, it is through critical reflection about our personal assumptions that we make meaning of the world. For teachers and learners, challenging our long established norms can lead to new understanding as long-held perspectives are transformed. For Friere ${ }^{[6-8]}$, hooks ${ }^{[9]}$, and Mezirow ${ }^{[10]}$, emancipatory educational efforts are of prime importance in a just society.

The persisting insights of Dewey, Friere, hooks, and Mezirow emerged with and provided contrast with the thinking of Tyler ${ }^{[16]}$ and Thorndike who portrayed learning as predictable, sequential, and measurable. For Thorndike, the causal order of sequenced learning fit well with an efficiency system process. Thorndike defined teaching as "the art of giving and withholding" ${ }^{[12]}$, where administrative experts hold the scientific knowledge and teachers toil to transfer that knowledge to students. Thorndike's offerings are present today in rating or grading scales that standardize and measure learning.

Ralph Tyler ${ }^{[16]}$ provided a model of curricula whereby students' experiences of content and subject matter are imposed by the teacher, in sequenced, measurable objectives. He accepted the importance of learning through hands-on experiences, but objectives determined, through needs assessment of the whole student population rather than the individual's needs were key for successful curriculum development. A model curriculum for Tyler included: goal setting; behavioral learning objectives; cumulative learning experiences; and standardized measurement of learner's performance. As Ironside ${ }^{[17]}$ states, the influences that persist from Tyler and Thorndike 'reinforce the modernist assumptions of a singular, objective conception of knowledge, truth, and rationality' (p. 86).

Contemporary nursing educators may recognize and be familiar with many of the ideas and contributions of educational theorists. Indeed, we suspect many nursing programs continue to be framed within a sequenced curriculum directed at achieving pre-defined learning outcomes established by expert teachers. In fact universities often require teachers to confine their courses to pre-approved learning outcomes endorsed by the University's centralized authority, the Senate. And, there are also educators of nursing who have taken-up the call from theorists advocating for reform and a shift to a Published by Sciedu Press 
more participatory and student-centred curriculum. Benner and colleagues ${ }^{[1]}$, Bevis and Watson ${ }^{[18]}$, Hills and Watson ${ }^{[19]}$, Hartrick ${ }^{[20]}$, and Diekelmann ${ }^{[21]}$, among others, encourage nurse educators to move from a behaviorist viewpoint to teaching/learning that is emancipatory with pedagogies that are empowering and context-dependent ${ }^{[17]}$.

Early in this century, Diekelmann ${ }^{[22-24]}$ and Ironside ${ }^{[25]}$ proposed a new pedagogy to enable reform in nursing education. Narrative Pedagogy (NP) arises from a bringing-together of interpretative and conventional pedagogies ${ }^{[17]}$. Enacting NP means engaging learners and teachers in thinking about thinking. Narrative pedagogy challenges our taken-for-granted educational practices and moves us away from courses which are built with the goal of delivering massive amounts of content to an approach that encourages teachers and learners to reveal their experiences of teaching, learning, and thinking.

For Diekelmann ${ }^{[22]}$, the narrative is both personal and collective. Narrative Pedagogy fosters new "teacher-learner relationships, student-centred education and curricula co-created” (p.247). The narrative approach elicits a community through examining educational practices as a nursing education collective-faculty and students coming-together with diversity of viewpoints so as to attend to common concerns. It creates the free space where teachers and learners can think anew and reinterpret practice through story and shared experiences. In this free space, multiple views and interpretations come forth as students and teachers consider the uncertainties and complexities of patients' lived experiences and nursing practice. Such open space to think and question contributes to the anticipated transformation in nursing education and leaves room for what Davis and Sumara ${ }^{[26]}$ call, emergent learning.

In spite of the calls and advances of some transformative thinkers in nursing education, Romyn ${ }^{[27]}$ argues that learning outcomes and the behaviorist model still exist in higher education for nurses, and so the theme of covering the content directed by teachers persists (Benner et al ${ }^{[1]}$; Diekelmann and Smythe ${ }^{[28]}$; Lindberg ${ }^{[4]}$. The practice of providing too much content fails to capture the lasting conceptual ideas that can be understood now and in the future ${ }^{[29]}$. The traditional topic-based curricula are being contested by educators and researchers such as Giddens and Brady ${ }^{[30]}$. When teachers and learners view nursing phenomena through a conceptual lens, they are inspired to investigate, analyze, and evaluate in deeper and more meaningful ways. We reflect how these concepts are transferable across contexts, situations, experiences; such that our understanding of an idea/concept becomes more complex ${ }^{[29]}$. Giddens and colleagues ${ }^{[31]}$ developed a nursing program situated in the cyberspace village called, The Neighborhood that is informed by a concept-based, narrative pedagogy (see, http://hsc.unm.edu/consg/neighborhood/). The Neighborhood was one of the inspirations for our own integration of narrative portals for engaging with nursing students. The narrative portals are elaborated below.

The complexity of nursing practice confronts our many educational traditions and calls for more real-life-like approaches that better prepare nurses to be with others, to be nimble in thought, to translate knowledge across contexts, and to know how to learn in the moments of nursing practice. In this paper we have integrated concepts of the major educational reform theorists described above, connected them with the insights of contemporary educators aligned with narrative pedagogy, concept-based learning, reflection, and complexity science. We turn now to the horizon of complexity and education before a more thoughtful consideration of how complexity can inform nursing education and propel the transformation of our educational processes and policies.

\section{Complexity science and education}

Complexity science is described as an ontology informing a multitude of disciplines in the sciences, arts, and humanities ${ }^{[32]}$. There are many excellent sources that contribute to the expanding awareness of this science of relationships and possibility ${ }^{[14,33-39]}$. In general, complexity science involves several key ideas that have wide appeal and applicability across disciplines. The central ideas of complexity science are that human beings and the universe we inhabit are living systems, complex adaptive systems where mutual process, non-linear change, networked connections, and transformations continually bring forth new realities and new possibilities. Specific concepts affiliated with complexity are: self- 
organization/autopoietic, emergence, unpredictability/non-linearity, and recursiveness ${ }^{[32,39]}$. Ricca ${ }^{[14]}$ proposes that “complex systems have three inter-related hallmarks: growth, mutual influence, and non-linearity” (p.32).

Self-organization is described differently by different authors. Most authors define it as a process of self-creation, growth, and becoming that emerges in patterns in relationship with others ${ }^{[35,37]}$. Ricca ${ }^{[18]}$ uses the term autopoietic "meaning they (complex systems) are self-directed and cannot easily be directed by external entities” (p.33). Goldstein ${ }^{[40]}$ suggests that "emergence is the arising of novel and coherent structures, patterns, and properties during the process of self-organization" (p.49). Self-organizing agents create new connections for specific purposes and generate new understanding and possibilities that would not be possible had they not joined ${ }^{[33]}$. Emergence and self-organization happen in non-linear and unpredictable ways. Complex systems do not perform like machines; they are open, generative, and self-directed according to their own histories, relationships, and purposes. As Smitherman states, "nonlinear dynamics look at interrelationships, connections, and blends of similarities and differences...not dichotomies of differences” ${ }^{[41]}$. (p.154)

Complexity science has informed development of educational theory and curricula development in many fields of study and multiple levels ${ }^{[14,42,43]}$, and two particular streams of work have influenced our transformations in nursing education. Specifically, we have been influenced by Davis, Sumara, and Luce-Kapler in their text, Engaging Minds ${ }^{[35]}$ and Complexity and Education ${ }^{[33]}$, and by Doll ${ }^{[36,44]}$ and Doll, Fleener, Truit, \& St. Julien ${ }^{[37]}$. As nurse educators we are called to attend to the process of complicity and choreography of knowledge-making and knowledge-acting —a process that requires full engagement with learners in their sense-making of relationships among personal and collective understandings. Davis and Sumara ${ }^{[26]}$ describe knowledge as possibility, as opposed to substance. From their perspective teaching-learning is a process of opening space for understanding and future acting. Knowledge has more to do with capacity than capability and students are inspired to learn how to learn in multiple contexts.

Doll ${ }^{[36,44]}$ proposes that in open complex adaptive systems, such as those created in nursing education among teachers/learners, there exists a place where transformation occurs and play and possibility reign and where "relationships and their patterns replace observation and data" ${ }^{[36]}$. He presented 4 Rs as a way to begin to imagine a pedagogy based in complexity. The 4 Rs are: richness, recursion, relations, and rigor ${ }^{[44]}$. We built on these 4 Rs to identify relevant teachinglearning processes: richness-maximize student choice for engaging course content according to interests and learning style; recursion-create learning opportunities open to students as they transfer concepts across multiple contexts (from local to global and personal to universal); relations - help students clarify and develop personal understanding about ideas, values, and actions in relation to chosen field of study, and rigor - scrutinize, enable, and provoke debate and dialogue among students in order to identify emergent learning and new insights from collegial engagement.

\subsection{Emergence of complexity in nursing education}

Marilyn Ray ${ }^{[45]}$ offered an overview of how nurse theorists in the last quarter of the 20st century had already integrated core ideas from complexity science and chaos theory to help nurses in practices attend to patterns, non-linearity, and expanding consciousness. Building on the visionary work of Martha Rogers ${ }^{[46]}$ in 1970, nurses have been working with ideas of complexity and unitary human beings and have developed deep understanding of how complexity can guide practice, research, and education. Integration of complexity science principles in nursing education may have lagged behind the practice and research advances over the past several decades, but nurse educators are publishing ${ }^{[4,47,48]}$ and the general environment of academe is, we believe, ready for the transformation. We chronicle our efforts with the hope of contributing to the emerging shift in the culture of curriculum and student engagement in nursing.

\subsection{Complexity-concept-based nursing education}

Frustrations with linear teaching methods and teacher-defined learning opportunities, the authors embarked on a process to create alternative structures to support teaching-learning in a more engaging, innovative, and open way. Our thinking is aligned with that of Young, Hayden-Mills, \& Brown ${ }^{[49]}$ who noted that nurse educators have a responsibility to teach nursing students how to think, how to conduct inquiry to inform thinking and acting with others, how to see and contribute 
to health patterns, and how to help create meaningful relationships. We embraced the power of story (narrative pedagogy), the frame of concept-based teaching-learning, intentional reflection, and the basic principles and possibilities of complexity science to develop curricular activities in an undergraduate and graduate nursing program. We chose these four influences of narrative, concept, reflection, and complexity for the following reasons:

- Enable students to be the directors of their own learning paths within the confines of relevant course concepts

- Engage students through narrative portals that develop deep and meaningful learning across contexts

- Benefit from the diversity of views and the plurality of truths

- Present students with critical questions of inquiry based on concepts instead of teacher-selected content

- Invite learning in community through dialogue, an inquiry of difference, and critical thinking.

Narrative, Concepts, Reflection, and Complexity in Undergraduate Nursing:

\section{An example}

In order to show how we have integrated complexity ideas in an undergraduate curriculum we provide an example of a plan and anticipated activities that will be constructed in an eLearning platform. We will describe how narratives provide portals for students to initiate an inquiry into the social determinants of health and the concerns of persons living with poverty. To begin, students select one narrative from a field of four-one from the perspectives of a man living on the streets in a large city, one of a single mother of two living in a shelter, one from a family in Haiti who are still recovering from the earthquake of 2010, and a fourth from an elderly couple in rural Canada. Students select a narrative that interests them and that they feel some connection with. Here is an example of a narrative presenting Ron's Story.

Ron is a neighbor who spends summers in the garden of the downtown church and at Tim Horton's during winter nights. Ron's friends in the church are Don, who operates the gift shop, and Marcel, the property manager. Both Don and Marcel provide Ron with company and food. Ron visits the church ‘drop-in’ twice a week for food and health care that is provided by the Parish Nurse. Ron has long standing health issues. One issue is his ongoing mental health experience with schizophrenia, and the other is a more recent experience of postural-dependent cellulitis of both legs. The Parish Nurse, Amy, has developed a relationship with Ron over many years and has come to understand the nuances of Ron's health issues. However, there are times when Amy is frustrated with Ron's refusal to be seen by a physician for the advancing cellulitis. At one point, Amy calls the Emergency Response Team from the local hospital. The team comes to the `drop-in` to accompany Ron to the ER for treatment. The police officer on the team reminds Amy that Ron cannot be forced to go to the ER with the team. After a lengthy conversation and many refusals from Ron, he finally agrees to go with the team.

In addition to engaging one of the narratives provided by the teacher, students are asked to search the web for additional narratives, video, research, and art work that depicts poverty in ways that influence health and quality of life. Students use search engines such as search-cube.com to seek multiple sources of information about poverty and health. Along with engaging narratives of poverty, students are introduced to one of several key concepts affiliated with the course. In this instance, students are asked to think about the concept of ethical relating and what that might look like for nurses engaged with persons living in poverty. Other key concepts include critical consciousness and social justice. We intend to create space in class discussion for students to share what they have learned about poverty, health, ethical relating, and social justice. Students bring additional narratives, art forms, insights, and connections among key ideas for sharing with the community. Since there are no right or wrong answers, students are free to describe their path of inquiry and the insights and understandings that were meaningful to them. When shared with the class, the learning is rich and nuanced as students consider the different insights described by others.

As the course evolves in the curricular plan, so do the narratives and complexities. Teachers can add detail to stories to introduce new concepts related to course content that require students to revisit concepts in new contexts and integrate 
additional complexities and realities. For example, teachers introduced the concept of ethical relating and added the following details to the emerging story involving the elderly couple living in rural Canada who cannot afford to keep their farm. The one adult son who could help them has just been diagnosed with a serious illness that restricts his ability to help his parents. The elderly father has been showing symptoms of early dementia and his wife is reluctant to let a physician into the home to examine him. Students are asked to revisit the idea of ethical relating in light of developments in the narrative. The narratives develop and become more complex which leads to the iterative/recursive process of looking anew. Students are asked to construct questions and perplexities linked with the concept of ethical relating and the family situation. The questions posed by various students can then be discussed in groups and students might be asked to prioritize their actions and directions for additional inquiry.

As students work their way through the narratives and concepts, the teacher enables the processes informed by complexity science: emergence with diversity, recursion/patterning, and transformative insights. Emergence with diversity relates to the ways connections among ideas emerge in the student's understanding and in the class discussions of narratives and concepts. Having diverse viewpoints is necessary for the emergence of novel patterns. Diverse views can challenge assumptions and provide alternative ways of thinking about and connecting ideas across contexts. In the example about poverty and ethical relating, for instance, students could consider shared health issues of accessibility and social justice for persons in a large urban city with persons in Haiti who live without housing three years after the 2010 earthquake disaster. Some students may justify social injustices in Haiti but not in wealthy countries like the United States and Canada, while others might have different views of global versus urban obligation and responsibilities.

Recursion/patterning is about how ideas revisited and reworked begin to form patterns of understanding and potential for action. Students might consider how ethical relating in the nurse-person process shifts across contexts. Once considered, specific values for respecting personhood surfaced as a persisting pattern of thought and actions across context. Creativity is enacted as students and teachers turn ideas upside down and remix understandings in unusual or unfamiliar ways in order to generate new ideas and connections not yet considered. In the poverty and ethical relating discussion students might question if professional groups should publicly align with political parties advocating improved access to health care resources. An unplanned discussion may emerge about individual versus collective obligation in just societies.

The final complexity notion transformative insight represents the aha moments and bifurcations in thinking. The sudden shifts in understanding that change everything in an instant. These transformative insights are generative of novel patterns in thinking and acting and represent how students self-organize and evolve. For instance, insights into the relationship between poverty and accessibility may lead students to realize that poverty also impacts how persons with diabetes take care of self and family. This new understanding may also change how nurses speak about and act with persons living with diabetes.

\subsection{Graduate curriculum and complexity science}

We have also developed specific teaching-learning activities informed by complexity science for use in a graduate qualitative research course. Students are introduced to the complexity approach at the beginning of term. The introduction includes basic ideas linked with emergence, recursion, creativity, and transformation. The educator provided references for engaging conceptual content related to qualitative research and students were asked to use the readings as a springboard for further inquiry. Questions were posed to help students go beyond the selected content. For instance, students were asked: "What concepts, ideas, or passages in the reading resonated with you? How do the ideas connect with your thinking or experience? What other literature or media (art, poetry, video) can you find to further your understanding of this concept, idea or passage? Please share what you find with members of the class. We have found additional software and search engines that help with complexity approaches and expressions (see for example: Prezi.com; wordle.com; tagxedo.com; search-cube.com; and spicynodes.org). 
Although early, our experience with a complexity approach in the online environment suggests that the levels of student engagement and enthusiasm with their own learning are noteworthy. The additional articles, artistic mediums and videos located by students contributed to class discussions went far beyond what an individual teacher might use. Material and resources found by students were rich and meaningful to other students and the teacher; further enhancing learning for the entire class. Once experienced, students and teachers began to trust the emergent learning and the possibilities for new insights and student contributions to the curriculum. Within that structure of concepts and key readings there was a great deal of freedom. "The sky is the limit," one student said. This interplay between structure and freedom, meaning, the enabling-constraints of the teaching-learning environment ${ }^{[26]}$ enhance the experiences for all involved.

Perturbations and challenges are welcome in complexity science pedagogy; they encourage reflection and possible reorganization. Honoring the frame of reference of learners ${ }^{[50]}$ is accomplished by asking how ideas and assumptions sit with the student's own views, understandings, and experiences. The course on qualitative research began with a question about what students already knew about qualitative inquiry. In order to address diversity and spark critical reflection educators might ask: "What tensions do you notice in the reading?" Or, "What assumptions do you detect in that work?" According to Doll ${ }^{[44]}$ teachers guided by complexity can act as the collective consciousness of the teaching-learning community; the teacher can summarize the concepts and ideas that resonated with the class over the week, list some of the questions that were raised, and the tensions identified. Guanglu ${ }^{[42]}$ links the teacher's responsibilities to attending to different views among students, realizing the locality of one's own thinking, and communicating "new forms of understanding through the fusion of horizons” (p. 97).

Interestingly, students experience the openness and freedom to explore and contribute. One student reflected upon the use of complexity theory to guide our online research class:

Complexity theory ideas that guide our learning are just phenomenal. The emergent learning is amazing! I was so curious myself to see how it would work out, and I think the number of postings and resources shared speaks volumes. I would not have learned nearly as much had the entire week been scripted... and yet the loose framework is so helpful as a guide to us all. Some of the concepts such as "working the hyphen" concept discussed in Lincoln ${ }^{[51]}$, are things that we may not have covered in a "typical" course. I found that particular piece about the hyphen astonishing in the insights it provided, not to mention the bracketing and feminist research discussions. I think that we each have a common base, then take what else we need. This is such an inspiring concept as it is clear that no one is obligated to read every resource. However, we become so CURIOUS that we WANT to scan everything, and as I mentioned can then concentrate in certain areas of interest. Thank you so much for having the courage and wisdom to try something a little bit different, with HUGE benefits for every single participant!

This is consistent with Jacobson and Wilensky's ${ }^{[52]}$ suggestion that, "Learning environments in which students come to experience and to construct their understandings about complex systems may be made more powerful—not to mention more interesting, engaging, and motivating" (p. 22). One issue that arose for students, evident in the above quote, was that with multiple postings each day, some students may find it difficult to keep up. In the complexity approach, students are not expected to follow every line of thinking or concept discussed. Rather, they stick with the ideas that resonate and delve deeper. The student has control of his/her inquiry and takes it in personally meaningful pathways. The teacher needs to make this clear to the students at the outset or the students can become overwhelmed. This is not to be confused with the experience of ambiguity and uncertainty that can often come before a new order of learning emerges from the mire. It is interesting to note that concepts often recur in multiple places and discussions over the course of a term. This is reflective of one of Doll's 4 R's discussed earlier, called recursion, meaning, to happen again ${ }^{[44]}$. Over a 12 week course it was interesting how the recursive process happened with key concepts in a natural and unplanned way.

Teaching can be far more stimulating when educators are open to surprise, to the collective consciousness of the group, and to the diversity of views and possibilities. On the other hand, when it is believed that there is one right way and one 
authoritative perspective, teachers spend time presenting and representing their personal views and students learn to look for the right answer. Teachers and students focused on right answers experience frustration and boredom. In contrast, discussion that is open to emergence, possibility, diversity and perturbations is deeper and more meaningful. One student wrote:

I am really enjoying this format. I am learning so much and because of the process you are facilitating and allowing it feels like a natural unfolding or revealing of understanding. It also prevents us from simply focusing on completing tasks such as reading a particular chapter or paper and answering the same question again and again until the poor last person is stuck trying to invent content that doesn't exist! It is learning and understanding that is simply evolving naturally. I enjoy and can already see this learning blossoming in each of us as we dialogue and support each other. It is helpful to have you jump in here and there to bring your knowledge, wisdom and perspective and to challenge us with another question or prompt. This gives everyone an opportunity to join in to the conversation with a fresh perspective regardless of when they can join the conversation.

We have found, like others ${ }^{[3]}$, that the use of the arts enhances scholarly understanding and expression. Art as an enabling-constraint fosters border-crossings, that is, exploring a concept through the arts and not simply from text. Participation in the online forum requires many of the key concepts of complexity where students are requested to provide their diverse perspectives, identify tensions in the readings, as well show that they can understand or explore the concepts in other disciplines such as through the arts (border-crossing).

\section{Evaluation of learning}

The dilemma of how to best evaluate learning that is an expression of the student's own self-organization and journey with the conceptual content is being worked on by us and various authors. It is necessary to document and evaluate what changes happen with complexity-inspired curricula. We are currently involved in work that will attend to questions of how to articulate and evaluate students participation with the process of study and inquiry, how to consider their expressions of growth, their new understanding and integration of knowing in action. We look forward to developments in this area and will be initiating systematic evaluation into our courses that integrate narratives, concepts, reflection, and complexity.

\section{References}

[1] Benner P, Sutphen M, Leonary V, Day L. Educating nurses: A call for radical transformation. San Francisco, CA: Jossey-Bass, 2010.

[2] Diekelmann N, Schekel M. Leaving the safe harbour of competency-based and outcomes education: Re-thinking practice education. J Nurs Educ. 2004; 43: 385-388. PMid:15478689

[3] Ewing B, Hayden-Miles M. Narrative pedagogy and art interpretation. J Nurs Educ. 2011; 50: 211-215. PMid:21323257 http://dx.doi.org/10.3928/01484834-20110131-01

[4] Lindberg CE. Lessons in complexity science: Preparing student nurses for practice in complex health care systems. In Nursing, Caring, and Complexity Science for Human-Environment Well-being. A. Davidson, MA. Ray, MC. Turkel, eds. New York, NY: Springer. 2011: 285-303. PMid:22029705

[5] Dewey J. Experience and education. New York: Simon \& Shuster, 1938.

[6] Freire P. Cultural action for freedom. Cambridge, MA, Harvard Educational Review and Centre for Study of Development and Social Change, 1970.

[7] Freire P. Pedagogy of the oppressed. New York: Herder and Herder, 1970.

[8] Freire P. Pedagogy of freedom. Ethics, democracy, and civic courage. Lanham, Maryland: Rowman \& Littlefield, 2001.

[9] hooks b. Teaching to transgress. New York: Routledge, 1994

[10] Mezirow J. Fostering critical reflection in adulthood: A guide to transformative and emancipatory learning. San Francisco: Jossey-Bass, 1990.

[11] Boisvert RD. John Dewey. Rethinking our time. New York, NY: State University of New York, 1998. 
[12] Tomlinson S. Edward Thorndike and John Dewey on the science of education. Oxford Rev Educ. 1997; 23: 365-383. http://dx.doi.org/10.1080/0305498970230307

[13] Semetsky I. Re-reading Dewey through the lens of complexity science, or: On creative logic of education. In Complexity Theory and Philosophy of Education. M. M. Mason, ed. Oxford, UK: Wiley-Blackwell. 2008: 79-90. http://dx.doi.org/10.1002/9781444307351.ch6

[14] Ricca B. Beyond teaching methods: A complexity approach. Complicity: Intern J Complex Educ. 2012; 9: 31-51.

[15] Berger PL. Pyramids of sacrifice: Political ethics and social change. Garden City: Anchor Books, 1976.

[16] Tyler RW. Basic principles of curriculum and instruction. Chicago, Illinois: University of Chicago, 1950.

[17] Ironside PM. Creating a research base for nursing education: An interpretative review of conventional, critical, feminist, postmodern, and phenomenologic pedagogies. Adv Nurs Sci. 2001; 23: 72-87. PMid:11225051

[18] Bevis EO, Watson J. Towards a caring curriculum: A new pedagogy for nursing. New York, NY: National League for Nursing, 1989.

[19] Hills M, Watson J. Creating a caring science curriculum: An emancipatory pedagogy for nursing. New York City, NY: Springer, 2011.

[20] Hartrick G. Transcending behaviouralism in communication education. J Nurs Educ.1999; 38: 17-22. PMid:9921783

[21] Diekelmann N. Curriculum revolution: A theoretical and philosophical mandate for change. New York: National League for Nursing. 1988. PMid:3174420

[22] Diekelmann, N. Student-centered pedagogies: Co-creating compelling experiences using new pedagogies. J Nurs Educ. 2004; 43: 245-247. PMid:15230302

[23] Diekelmann N. Engendering community: Learning to live together. J Nurs Educ. 2002; 42: 243-244.

[24] Diekelmann N. Engaging the students and the teacher: Co-creating substantive reform with narrative pedagogy. J Nurs Educ. 2005; 44: 249-252. PMid:16021800

[25] Ironside PM. New pedagogies for teaching thinking: The lived experiences of students and teachers enacting narrative pedagogy. $\mathrm{J}$ Nurs Educ. 2003; 42: 509-516. PMid:14626389

[26] Davis B, Sumara D. Complexity as a theory of education. Transnational Curric Inq. 2008; 5(2), http://nitinat.library.ubc.ca/ojs/index.php/tci.

[27] Romyn DM. Disavowal of the behaviourist paradigm in nursing education: What makes it so difficult to unseat? Adv Nurs Sci. 2001; 23: 1-10. PMid:11225046

[28] Diekelmann N, Smythe E. Covering content and the additive curriculum: how can I use my time with students to best help them learn what they need to know? J Nurs Educ. 2004; 43: 341-344. PMid:15344369

[29] Erikson HL. Ed. Stirring the heart, head and soul: Redefining curriculum, instruction, and concept-based learning (3rd. ed.). Thousand Oaks, CA: Corwin, 2008.

[30] Giddens JF, Brady DP. Rescuing nursing education from content saturation: The case for a concept-based curriculum. J Nurs Educ. 2007; 46: 65-69. PMid:17315564

[31] Giddens J, Brady D, Brown P, Wright M, Smith D, Harris J. A new curriculum for a new era in nursing education. Nurs Educ Perspect. 2008; 29: 200-204. PMid:18770947

[32] Gough N. Complexity, complexity reduction, and 'methodological borrowing' in educational inquiry. Complicity: Intern J Complex Educ. 2012; 9: 41-56.

[33] Davis B, Sumara D. Complexity and education: Inquiries into learning, teaching, and research. New York, NY: Routledge, 2006.

[34] Davis B, Sumara D. Fitting teacher education in/to/for an increasingly complex world. Complicity: Int J Complex Educ. 2012: 30-40.

[35] Davis B, Sumara D, Luce-Kaplar R. Engaging minds: Changing teaching in complex times (2nd ed.). New York, NY: Routledge, 2008.

[36] Doll WE. Complexity and the culture of curriculum. Complicity Intern J Complex Educa. 2012; 9: 10-29.

[37] Doll WE, Fleener MJ, Truit D, St. Julien J. Eds. Chaos, complexity, curriculum, and culture. A conversation. New York, NY: Peter Lang, 2008.

[38] Mason M. ed. Complexity theory and the philosophy of education. Oxford, UK: Wiley Blackwell, 2008. http://dx.doi.org/10.1002/9781444307351

[39] Fenwick T. Puzzling 'responsibility' in complexity and education. In Proceedings of the Complexity Science and Educational Research Conference. 18-20 February 2007 Vancouver B.C. 2007: 99-110. www.complexityandeducation.ca

[40] Goldstein J. Emergence as a construct: History and issues. Emergence: J Complex Issues Organiz Manag. 1999; 1: 49-72.

[41] Smitherman S. Chaos and complexity theories. Wholes and holes in curriculum. In Chaos, Complexity, Curriculum, and Culture. A Conversation. WE Doll, MJ Fleener, D Truit, J. St. Julien, eds. New York, NY: Peter Lang. 2008: 153-180. 
[42] Guanglu Z. On the recursion between teaching and learning. Complicity: Intern J Complex Educ. 2012; 9: 90-97.

[43] Morgan G, Adams J. Pedagogy first: Making web-technologies work for soft skills development in leadership and management education. J Interact Learn Res. 2009; 20: 129-155.

[44] Doll WE. A post-modern perspective on curriculum. New York: Teachers College, 1993.

[45] Ray M. Complexity and nursing science. Nurs Sci Q. 1998; 11: 91-93. PMid:9923319 http://dx.doi.org/10.1177/089431849801100302

[46] Rogers ME. An introduction to the theoretical basis of nursing. Philadelphia, F. A. Davis, 1970.

[47] Hodges HF. Preparing new nurses with complexity science and problem-based learning. J Nurs Educ. 2011; 50: 7-13. http://dx.doi.org/10.3928/01484834-20101029-01

[48] James K. Incorporating complexity science theory into nursing curricula. Creative Nurs. 2010; 16: 137-142. PMid:20879623 http://dx.doi.org/10.1891/1078-4535.16.3.137

[49] Young P, Hayden-Miles M, Brown P. Narrative pedagogy. In Teaching Nursing: the Art and Science. L. Caputi ed. Glen Ellyn, IL: College of DuPage. 2009: 805-836. PMid:20012860

[50] Watson J. Nursing: the philosophy and science of caring. Denver, Colorado: University of Colorado, 2008.

[51] Lincoln YS. “What a long, strange trip it’s been...”: twenty-five years of qualitative and new paradigm research. Qual Inq. 2010; 16: 3-9. http://dx.doi.org/10.1177/1077800409349754

[52] Jacobson MJ, Wilensky U. Complex systems in education: Scientific and educational importance and implications for the learning sciences. J Learn Sci. 2006; 15: 11-34. http://dx.doi.org/10.1207/s15327809jls1501_4 